\title{
シンポジウム「新時代平衡機能検査」
}

\author{
前庭機能検査の過去と未来 \\ 一VEMP を中心に 平成から令和へ一
}

\author{
坪田 雅仁・室伏 利久
}

\section{The past and future of vestibular functional testing}

-From the Heisei to the Reiwa period-

\author{
Masahito Tsubota, Toshihisa Murofushi
}

Department of Otolaryngology, University Hospital, Mizonokuchi Teikyo University School of Medicine

Vestibular function testing is very important for establishing the correct diagnosis of vertigo and dizziness, and is especially helpful for isolating the affected side and the responsible lesion. Until the end of the Showa period, caloric nystagmus was the gold standard for this examination, but it was inadequate to examine the otolith function. During the Heisei period, vestibular evoked myogenic potential (VEMP) and video head impulse test (vHIT) were introduced, which enable detailed examination of the functions of the inner ear and vestibular nerve. In these examinations, cervical VEMP (cVEMP) is used to evaluate the sacculus, and inferior vestibular nerve function, which examination is used to evaluate vestibular neuritis, acoustic neuroma, and superior semicircular canal dehiscence. Until now, endolymphatic hydrops was detected using glycerol-or furosemide-loaded cVEMP; however, these tests have side effects, such as headache, and take several hours to perform. To address these concerns, we introduced the tuning property test and confirmed its diagnostic usefulness. The tuning property test is very useful because it does not require any drugs and can be completed in a short time. During the Reiwa period, additional research on the properties and clinical usefulness of the tuning property test are needed.

Key words: vestibular evoked myogenic potential (VEMP), Meniere's Disease, tuning property test

\section{はじめに}

めまい診療において, 前庭機能検査は病巣・病態 診断などに有用である。本稿ではこれまでの主な前 庭機能検査についての歴史や新しい知見, 今後の課 題などにつき前庭誘発筋電位（vestibular evoked myogenic potential：VEMP）を中心に報告する。

帝京大学医学部附属溝口病院耳鼻咽喉科

\section{前庭機能検查のこれまでの流れ}

めまい診療を行うにあたり最初は問診や簡易検査 を行うが，この時点で良性発作性頭位めまいや前庭 性片頭痛など比較的容易に診断がつくものもあれ ば，診断のためにより詳細な前庭機能検査を要する ものも存在する。めまいの診断において, 前庭機能 検查に求められることは(1)患側や病変部（半規管か 耳石器か) の推定(2)内リンパ水腫のような病態把握 


\section{$\mathrm{VHIT}$}

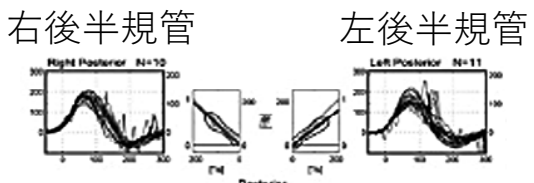

右外側半規管

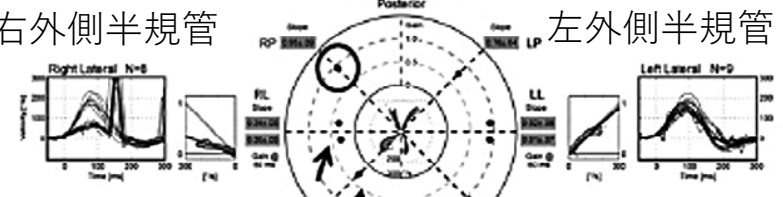

右前半規管
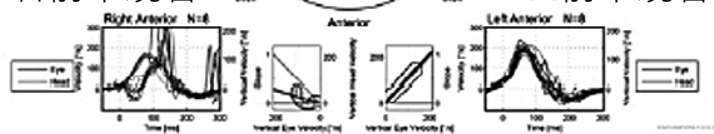

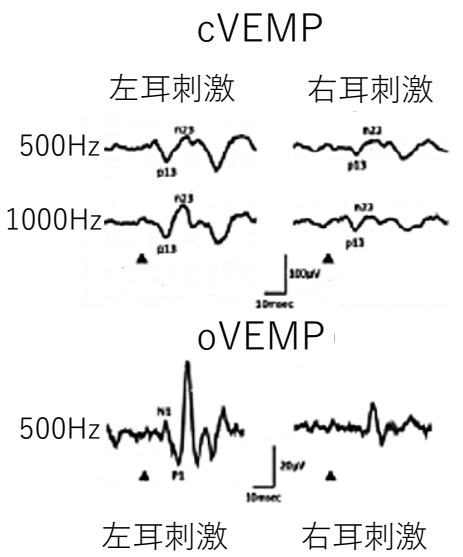

図 1 右上前庭神経炎の VEMP およびvHIT 所見（文献 3 より引用，一部改変）

vHIT にて右外側半規管，前半規管の catch up saccade およびVOR gain の低下を 認める。また, cVEMP は両側とも反応を認めるが oVEMP は右耳刺激にて反応消 失を認める。

A

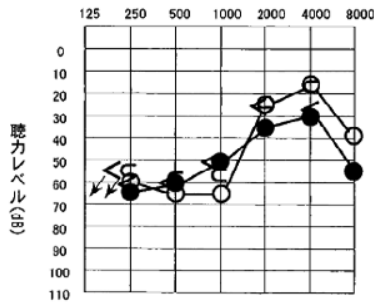

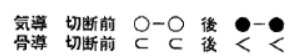

VN切断前
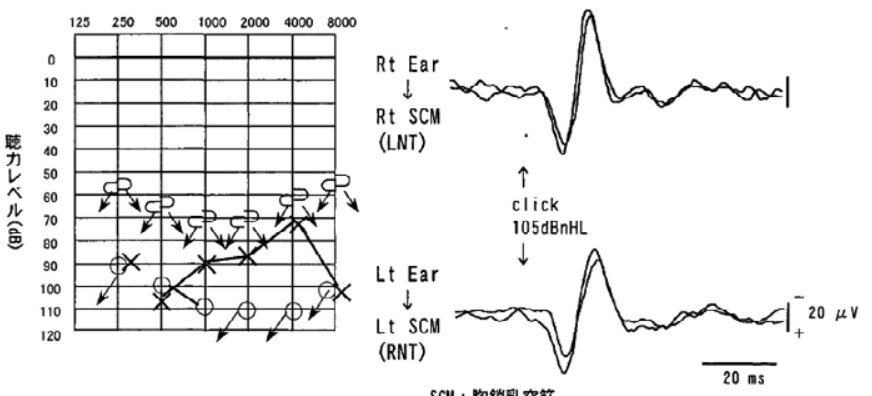

SCH : 詾鎖乳突筋

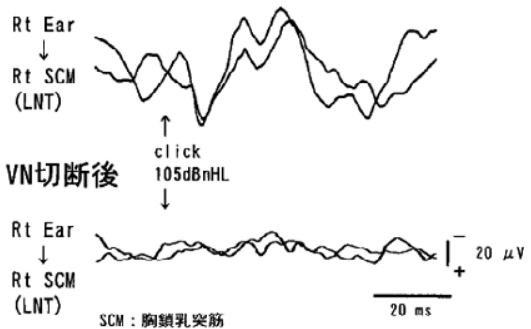

B

図2＼cjkstart前庭神経（VN）切断前後および高度難聴患者での cVEMP（文献 4 より引用)

$\mathrm{A}$ ：前庭神経切断前後の $\mathrm{cVEMP}$ 。前庭神経切断にて反応消失を認 める。

$\mathrm{B}$ ：両側高度感音難聴症例での cVEMP：両側とも良好な反応を認 める。

が挙げられる。前庭機能検査として, 昭和時代まで は温度刺激検査（カロリックテスト）が主に用いら れてきた。この検查は比較的簡便であり，外側半規
管の評価を左右別に評価できる点で優れているが, 耳石器や前・後半規管の評価が行えないという課題 があった。平成時代に入り VEMPが報告され ${ }^{122)}$, 


\section{上前庭神経切断前}

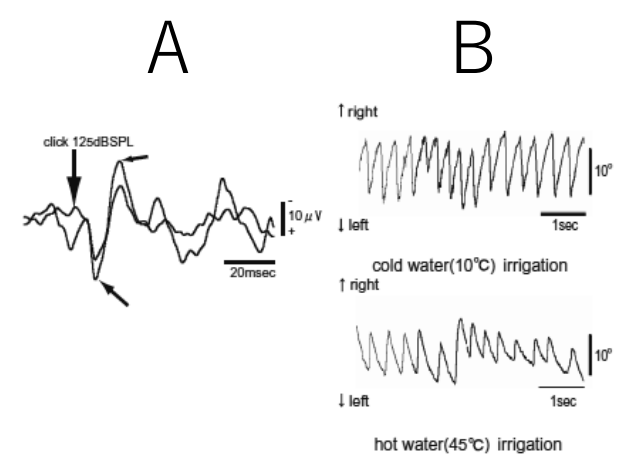

上前庭神経切断後

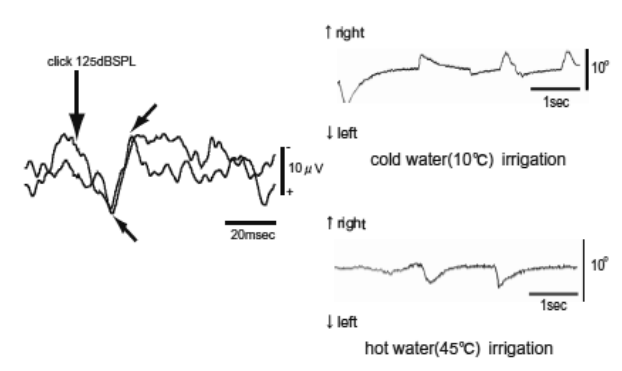

図３上前庭神経切断後のサルの $\operatorname{cVEMP}(\mathrm{A})$ とカロリックテスト（B） (文献 5 から引用)

上前庭神経切断にてカロリックテストでは反応が消失したが cVEMPは反応が維持された。

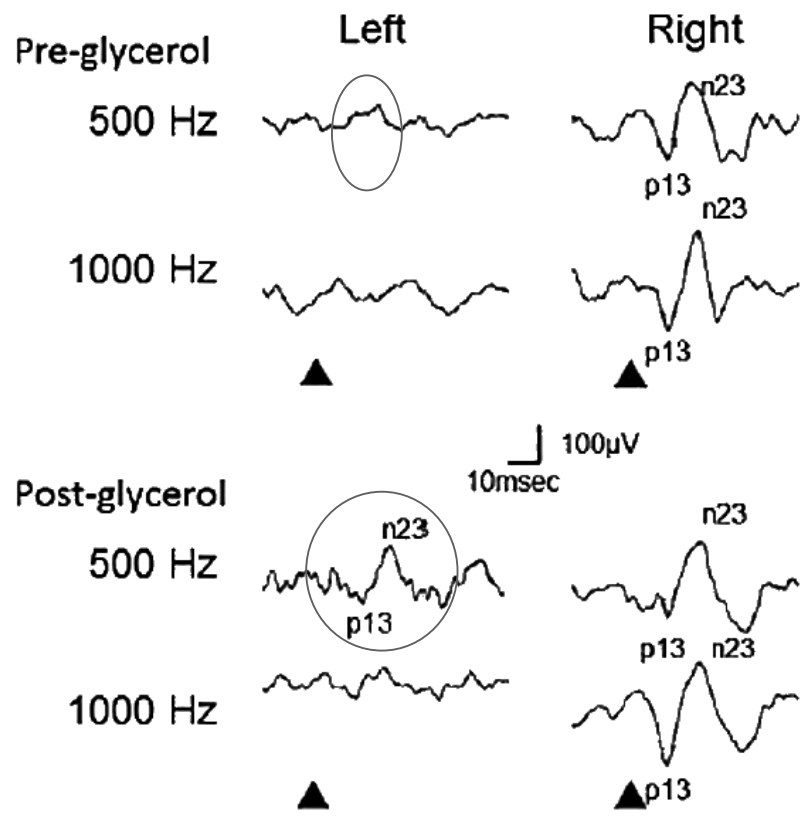

図4 左メニエール病症例におけるグリセロール負荷 前後の cVEMP（文献23より引用）

グリセロール投与にて左側の cVEMP の反応増 大が見られる。

これまで評価が困難であった球形囊・卵形囊が左右 別に評価可能となった。さらに，平成後半には
vHIT (video head-impulse test, ビデオヘッドイン パルステスト）が導入され，外側半規管だけでなく 前・後半規管の評価が可能となった。これにより, 図 1 のような症例 ${ }^{3)}$ で前庭神経炎などの詳細な病巣 診断が可能になった。以上より, 平成時代は前庭機 能検査発展への一時代だったと言うことができる。 前庭誘発筋電位検査 Vestibular evoked myogenic potential : VEMP

VEMPは強大音刺激にて誘発される反応であ り，胸鎖乳突筋に誘発される cervical VEMP (cVEMP) と外眼筋に誘発される ocular VEMP (oVEMP) がある。cVEMPは1992年に Halmagyi と Colebatchにより初めて報告1)された強大音刺激 により胸鎖乳突筋に誘発される筋電位である。図 2 の通り，この反応は高度難聴患者で消失せず，前庭 神経切断を行った患者では消失することから前庭由 来の反応であると考えられている゙。過去に Tsubota らが行った動物実験5)において, 図 3 に示 す通り上前庭神経を選択的に切断することにより維 持されることから, 本反応は球形囊一下前庭神経由 来の反応と考えられている。また, oVEMP は2005 年に Rosengren らにより報告された筋電位 ${ }^{2}$ であ 
A

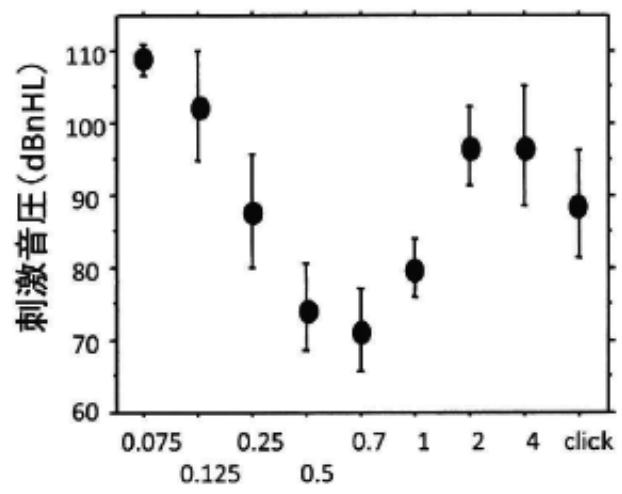

刺激周波数
B

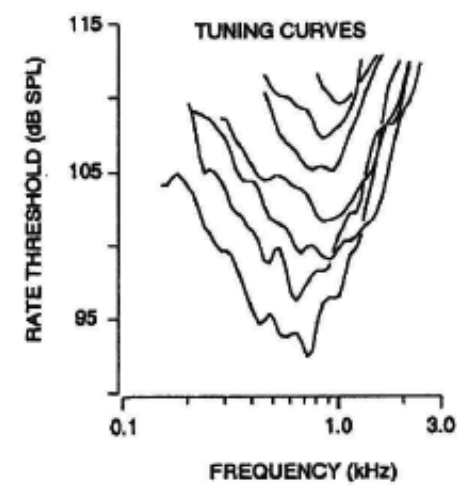

$(\mathrm{kHz})$

図 5 cVEMP および球形囊神経の周波数特性

(A)ヒトの cVEMP の周波数特性（文献20より引用）

(B)ネコの球形囊神経の周波数特性（文献21より引用)

いずれも500から $1000 \mathrm{~Hz}$ にかけての閾值が最も低い。

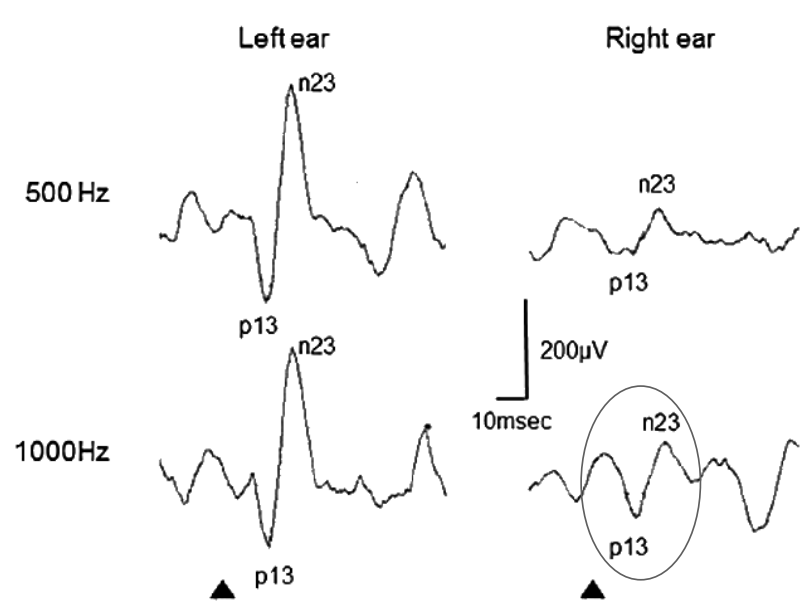

図6＼cjkstart右メニエール病患者における tuning property test（文献24から引用）

右耳は振幅に関して, $500 \mathrm{~Hz}$ に対して $1000 \mathrm{~Hz}$ 優位である。

り，この反応は卵形囊一上前庭神経の評価を反映し ていると考えられている6。

この二つの筋電位の報告以降, 耳石器の機能評価 が臨床的に行えるようになり，前庭神経炎》だけで はなく突発性難聴8), 聴神経腫瘍910), 多発性硬化

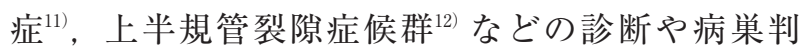
定・予後判定などに応用されるようになった。

\section{内リンパ水腫推定検査一cVEMP を用いた新しい} 検查法一

めまい疾患の病巣診断において平成時代に格段の 進歩をとげた前庭機能検査であるが, メニエール病 のように日常診療においては病態診断が必要な場面 にも遭遇する。以下，メニエール病に扔ける内リン パ水腫推定検查の過去と最近の知見を報告する。

昭和から平成前半にかけ，内リンパ水腫推定検査 として蝸電図, グリセロール負荷試験（聴力検 查), フロセミド負荷試験（回転検查や温度刺激検 查）などが行われてきた ${ }^{1314}{ }^{14}$ が，平成後半にはフロ セミド及びグリセロール負荷 VEMP ${ }^{1516)}$ ，さらには 内耳造影 $\mathrm{MRI}^{17}$ が導入され有用性が報告されてき た。これらの検査を組み合わせることによって診断 率が向上するものの, 検査においては侵襲性, 薬剤 アレルギー，検査に要する時間，コスト面などの問 題点があり解決が望まれていた。

内リンパ水腫は前庭の中でも球形囊に生じやすい という報告 ${ }^{1819)}$ があり，このことから cVEMPを用 いた球形囊における内リンパ水腫の推定がその診断 に有用であると考えられる。図 4 に示すように，従 来はグリセロールやフロセミド負荷による cVEMP の振幅増大が䛦断に用いられており有用性が報告さ れてきた ${ }^{1516)}$ が，前述したような問題点を抱えてお 
り，より簡便な内リンパ水腫推定の検査方法の開発 が望まれていた。そこで, 我々は cVEMPの周波数 特性に着目した。図 5 に示す通り,これまでのヒト に扮ける臨床研究20) や動物実験21) の結果から, cVEMP は間值が最も低くなり振幅が大きくなる特 徵周波数が $500 \mathrm{~Hz}$ から $700 \mathrm{~Hz}$ の間にあると報告さ れているが, メニエール病では特徴周波数が 1000 $\mathrm{Hz}$ 側にシフトするという報告22) がなされている。 これらの報告を応用し, 我々は $500 \mathrm{~Hz}$ と $1000 \mathrm{~Hz}$ の cVEMP の振幅を比較し内リンパ水腫の存在を推 定する検査である tuning property test を開発し報 告した ${ }^{23)}$ 。具体的な計算式については, $(500 \mathrm{~Hz}$ の 振幅值 $-1000 \mathrm{~Hz}$ の振幅值 $/ 500 \mathrm{~Hz}$ の振幅值 +1000 $\mathrm{Hz}$ の振幅值) $\times 100$ とし, <-19.9 で陽性と判定し ている。典型例では図 6 のようにメニエール病患者 では患側の $1000 \mathrm{~Hz}$ の振幅が $500 \mathrm{~Hz}$ の振幅と比較 して増大する。この方法について, グリセロール VEMP の陽性率との相関を調べたところ有意な相 関を認め ${ }^{23)}$, 他の疾患と比較してもメニエール病に おいて有意に陽性率が高いことが示された ${ }^{24)}$ 。ま た，めまいを繰り返すという点で鑑別にあがる前庭 性片頭痛との鑑別に㧍ける有用性についても報告し た24)。少数例による検討ではあるが， 3 T Gd-MRI に扔ける内リンパ水腫の grading の結果との相関も 示唆されている ${ }^{25)}$ 。本検査は短時間で終わり薬剤投 与等の侵襲もないことから, 新しい内リンパ水腫推 定検査として有用であると考えられる。

\section{おわりに}

めまい診断における前庭機能検査の変遷について 概説した。VEMPの開発と発展はめまい平衡医学 における診断学において大きな進歩の一つであると 考えられる。球形囊の周波数特性に着目した Tuning property testは短時間で済み, かつ侵襲が少ないと いう点で有用な検査であると考えられ，今後は他の 内リンパ水腫推定検査との比較, メニエール病治療 前後の比較, 臨床経過との関連などとの検討が必要 と考えられた。

\section{文献}

1 ) Colebatch JG, Halmagyi GM: Vestibular evoked potentials in human neck muscles before and after unilateral vestibular deafferentation. Neurology 42: 1635-1636, 1992
2 ) Rosengren SM, McAngus Todd NP, Colebatch JG: Vestibular-evoked extraocular potentials produced by stimulation with bone-conducted sound. Clin Neurophysiol 116: 1938-1948, 2005

3 ）室伏利久：VEMP の臨床応用 update. Equilibrium Res 77: 264-270, 2018.

4) 將積日出夫, 竹森節子, 渡辺行雄 : 前庭誘発筋 電位. Equilibrium Res 59: 186-192, 2000

5 ) Tsubota M, Shojaku H, Hori E, et al.: Effects of vestibular nerve section on sound-evoked myogenic potentials in the sternocleidomastoid muscle of monkeys. Clin Neurophysiol 118: 1488-1493, 2007

6 ) 岩㠃真一: 気導刺激と骨導刺激, OVEMP と cVEMPをどのように使い分けるか？ Equilibrium Res 72: 198-203, 2013

7 ) Chihara Y, Iwasaki S, Murofushi T, et al.: Clinical characteristics of inferior vestibular neuritis. Acta Otolaryngol 132: 1288-1294, 2012

8) Nagai N, Ogawa Y, Hagiwara A, et al.: Ocular vestibular evoked myogenic potentials induced by bone-conducted vibration in patients with unilateral inner ear disease. Acta Otolaryngol 134: 151-158, 2014

9) Ushio M, Iwasaki S, Chihara Y, et al.: Is the nerve origin of the vestibular schwannoma correlated with vestibular evoked myogenic potential, caloric test, and auditory brainstem response? Acta Otolaryngol 129: 1095-1100, 2009

10) Ushio M, Iwasaki $S$, Murofushi $T$, et al.: The diagnostic value of vestibular evoked myogenic potential in patients with vestibular schwannoma. Clin Neurophysiol 126: 1149-1153, 2009

11) Murofushi T, Shmizu K, Takegoshi H, et al.: Diagnostic value of prolonged latencies in the vestibular evoked myogenic potential. Arch Otolaryngol Head Neck Surg 127: 1069-1072, 2001

12) Welgampola MS, Myrie OA, Minor LB, et al.: Vestibular evoked myogenic potential thresholds normalize on plugging superior canal dehiscence. Neurology 70: 464-472, 2008 
13）麻生 伸, 水越鉄理, 大井秀哉, 他：メニエー ル病の蝸電図所見 グリセロールテストとの比 較.耳鼻臨床補冊 8 ：242-248, 1986

14）伊東宗治, 將積日出夫, 小林英人, 他 : メ二エ ール病抒よび類似疾患に対するフローセミド VOR 検査の臨床的検討. Equilibrium Res Suppl 4: 68-72, 1988

15) Seo T, Node M, Yukimasa A, et al.: Furosemide loading vestibular evoked myogenic potential for unilateral Meniere's disease. Otol Neurotol 24: 283-288, 2003

16) Magliulo G, Cuiuli G, Gagliardi M, et al.: Vestibular evoked myogenic potentials and glycerol testing. Laryngoscope: 338-343, 2004

17) Naganawa S, Sugiura M, Kawamura M, et al.: Imaging of endolymphatic fluid at $3 \mathrm{~T}$ after intratympanic administration of gadoliniumdiethylene-triamine pentaacetic acid. Am J Neuroradiol 29: 724-726, 2008

18) Okuno T, Sando I: Localization, frequency, and severity of endolymphatic hydrops and pathology of the labyrinthine membrane in Meniere's disease. Ann Otol Rhinol Laryngol 96: 438-445, 1987

19) Lin MY, Timmer FCA, Oriel BS, et al.: Vestibular evoked myogenic potentials (VEMP) can detect asymptomatic saccular hydrops. Laryngoscope 116: 987-992, 2006
20）將積日出夫：VEMP の基礎研究の可能性. Equlibrium Res 72: 204-209, 2013

21) McCue MP, Guinan JJ Jr: Spontaneous activity and frequency selectivity of acoustically responsive vestibular afferents in the cat. J Neurophysiolo 74: 1563-1572, 1995

22) Rauch SD, Zhou G, Kujawa SG, et al.: Vestibular evoked myogenic potentials show altered tuning in patients with Meniere's disease. Otol Neurotol 25: 333-338, 2004

23) Murofushi T, Komiyama S, Suizu R: Detection of saccular endolympathic hydrops in Meniere's disease using a modified glycerol cVEMP test in combination with the tuning propery test. Otol Neurotol 37: 1131-1136, 2016

24) Murofushi T, Tsubota M, Suizu R, et al.: Is alteration of tuning property in cervical vestibularevoked myogenic potential specific for Meniere's disease? Front Neurol 8: 193, 2017 doi: 10.3389/fneur.2017.00193

25）室伏利久, 坪田雅仁, 水津亮太, 他：メニエー ル病およびその類縁疾患における cVEMP tuning propertyによる内リンパ水腫推定と MRI 所見は一致するか? 第29回日本耳科学会総会 学術講演会抄録集：343, 2019

利益相反に該当する事項はない。 